\title{
Pengaruh model aktivitas jasmani berbasis perseptual motorik terhadap gerak dasar manipulatif anak taman kanak-kanak
}

\section{The influence of physical activity model based on perceptual motor skills on kindergarten students' manipulative fundamental motor}

\section{Yudanto}

Department of Sport Education, Faculty of Sport Science, Universitas Negeri Yogyakarta, Jl. Colombo No.1, Karang Malang, Caturtunggal, Depok, Sleman District, Special Region of Yogyakarta, 55281, Indonesia.

Received: 12 December 2019; Revised: 25 March 2020; Accepted: 7 April 2020

\section{Abstrak}

Gerak dasar perlu dikembangkan pada anak taman kanak-kanak. Gerak dasar merupakan dasar untuk mempelajari dan mengembangkan berbagai keterampilan teknik dalam berolahraga dan aktivitas fisik. Penelitian ini bertujuan mengetahui pengaruh model aktivitas jasmani berbasis perseptual motorik terhadap gerak dasar manipulatif anak taman kanak-kanak. Penelitian ini merupakan penelitian pra eksperimen, dengan desain penelitian one group pre test and postest design. Subjek penelitian adalah anak taman kanak-kanak yang berjumlah 25 siswa. Instrumen penelitian adalah Test of Gross Motor Development-2 (TGMD-2) dari Ulrich. Analisis data menggunakan uji t, dengan membandingkan rata-rata hasil tes awal dengan rata-rata hasil tes akhir. Hasil penelitian gerak dasar manipulatif, yang meliputi memukul bola diam, memantulkan bola di tempat, menangkap, menendang, lemparan atas, dan lemparan bawah, menunjukkan nilai sig. $0.000<0.05$, maka dapat disimpulkan ada pengaruh yang signifikan model aktivitas jasmani berbasis perseptual motorik terhadap gerak dasar manipulatif anak taman kanak-kanak. Hasil ratarata tes akhir kemampuan memukul bola diam, memantulkan bola di tempat, menangkap, menendang, lemparan atas, dan lemparan bawah lebih besar dibandingkan dengan hasil rata-rata tes awal. Penelitian ini hanya terbatas pada satu sekolah taman kanak-kanak Kelas B yang berusia 5-6 tahun.

Kata kunci: aktivitas perseptual motorik, gerak dasar manipulatif, taman kanakkanak.

\begin{abstract}
Fundamental motor learning is important for kindergarten students. Fundamental motor is the foundation for learning and developing various techniques in sports and physical activity. This study aims to determine the effect of perceptual motorbased physical activity models on the manipulative fundamental motor of kindergarten students. This research is a pre-experimental research, with one group pretest and posttest research design. Research subjects are 25 kindergarten students. The research instrument is the Test of Gross Motor Development-2 (TGMD-2) of Ulrich. Data analysis employs $t$ test, by contrasting the average initial test results with the average final test results. The research results of manipulative fundamental motor, consisting of, striking stationary ball, stationary dribble, catch, kick, overhand throw, and underhand roll show the
\end{abstract}

Correspondence author: Yudanto, Universitas Negeri Yogyakarta, Indonesia.

Email: yudanto@uny.ac.id 
value of sig. $0.000<0.05$. Hence, it indicates a significant effect of the physical activity based on perceptual motor skills on kindergarten students' manipulative fundamental motor. The final test result average of the ability to striking stationary ball, stationary dribble, catch, kick, overhand throw, and underhand roll is greater than the average results of the initial test. This research is conducted on 5-6 years old children of Class $B$ in a kindergarten.

Keywords: kindergarten students, manipulative fundamental motor, perceptual motor skills.

\section{PENDAHULUAN}

Masa prasekolah merupakan masa perkembangan yang menyeluruh atau holistik. Perkembangan yang terjadi pada masa ini meliputi kognitif, fisik motorik, emosi, dan psikososial. Anak pada masa ini juga disebut masa emas (golden age). Masa keemasan merupakan masa pertumbuhan dan perkembangan pesat pada otak (Affrida, 2017). Aspek perkembangan gerak yang terjadi pada masa prasekolah sejalan dengan pertumbuhan dan perkembangan fisiknya. Stimulasi yang mengarah pada pertumbuhan dan perkembangan anak menjadi perhatian utama, karena pertumbuhan dan perkembangan yang optimal akan berdampak pada berkembangnya otak, emosi, fisik, dan sosial yang optimal pula (Hidayatullah, 2019). Stimulasi pada masa prasekolah khususnya dalam pengembangan kemampuan gerak dasar pada anak taman kanak-kanak sangat diperlukan. Kemampuan gerak dasar pada usia dini sangat penting untuk dipelajari, apabila anak kurang cukup diajarkan tentang gerak dasar, maka anak akan mengalami berbagai hambatan dalam mempelajari dan melakukan berbagai keterampilan gerak yang lebih sulit di kemudian hari, seperti mempelajari keterampilan teknik olahraga di kemudian hari (Bakhtiar, 2015). Usia prasekolah dan tahun-tahun awal sekolah dasar sangat penting untuk pengembangan dan penguasaan kemampuan gerak dasar (Hardy et al., 2010).

Gerak dasar merupakan gerakan-gerakan dasar yang berkembangnya sejalan dengan pertumbuhan tubuh dan tingkat kematangan pada anak. Pada dasarnya kemampuan gerak dasar mencakup lokomotor, non lokomotor, dan manipulatif (Sugiyanto, 2005). Gerak dasar non lokomotor adalah gerakan melibatkan kaki atau tangan 
dan togok, yang merupakan gerakan tanpa berpindah tempat atau berporos di suatu sumbu pada bagian tubuh tertentu, contohnya membungkuk, memutar tangan/lengan, memutar togok, dan mengayun tungkai/kaki. Gerak dasar lokomotor adalah gerakan yang disertai dengan berpindah tempat, contohnya berjalan, berlari, merangkak, lompat, dan meluncur. Gerak dasar manipulatif dicirikan dengan adanya gerakan memainkan atau memanipulasi suatu objek. Gerakan ini melibatkan kaki, tangan atau bagian tubuh yang lain. Pelaksananan gerak manipulatif membutuhkan koordinasi atau melibatkan bagian tubuh dengan indera peraba dan penglihatan ketika memanipulasi objek, contohnya memainkan bola menggunakan kepala, menggunakan tangan atau kaki.

Stimulasi kemampuan gerak dasar diperlukan karena tidak semua anak mengalami perkembangan gerak secara normal. Berdasarkan penelitian (Rachman \& Anggita, 2018), telah mengukur 106 anak TK untuk mengetahui kemampuan motorik halus dan kasar. Dari 106 anak TK diperoleh hasil kemampuan motorik kasar adalah sebanyak 19 anak berkategori sangat baik, 55 anak berkategori baik, 30 anak berkategori cukup, dan 2 anak berkategori kurang. Sedangkan kemampuan motorik halus disimpulkan bahwa 7 anak berkategori sangat baik, 38 anak berkategori baik, 53 anak berkategori cukup, 6 anak berkategori kurang, dan 2 anak berkategori kurang sekali (Rachman \& Anggita, 2018). Berdasarkan uraian tersebut, kiranya perlu dilakukan pengkajian lebih lanjut terhadap perkembangan gerak anak prasekolah dengan memberikan stimulasi untuk membantu anak prasekolah dalam mencapai perkembangan geraknya sesuai dengan tahap perkembangan gerak yang semestinya. Pemberian stimulasi melalui aktivitas perseptual motorik yang diberikan kepada anak prasekolah yang sesuai dengan tahap perkembangan anak prasekolah perlu dilakukan.

Masa anak taman kanak-kanak disebut juga masa bermain, sehingga aktivitas jasmani yang diberikan lebih banyak ke arah bermain. Aktivitas yang memuat unsur-unsur perseptual motorik sangat penting diberikan pada anak taman kanak-kanak. Hal ini sesuai dengan hasil 
beberapa penelitian, diantaranya: 1) ada hubungan kemampuan akademik dengan kemampuan perseptual motorik (Nourbakhsh, 2006), 2) kemampuan mengeja, membaca, dan matematika anak usia 4-6 tahun dipengaruhi oleh perseptual motorik dalam hal kinestetik, visual, dan auditori (Dhingra et al., 2010), 3) keterampilan kognitif anak prasekolah dipengaruhi oleh aktivitas jasmani yang terprogram dalam periode tertentu (Hosseini et al., 2011), 4) prestasi akademik dipengaruhi oleh perseptual motorik, anak memiliki kognitif yang baik apabila didukung oleh perseptual motorik yang baik pula (Morales et al., 2011), 5) kemampuan motorik memiliki hubungan dengan kinerja akademik, dalam matematika bagi anak kelas 1 sekolah dasar (Macdonald et al., 2020), 6) perseptual motorik memiliki hubungan dengan kemampuan gerak dasar pada anak usia 5-7 tahun (Hyungmin \& Johan, 2012), 7) intervensi program perseptual motorik pada anak usia 6-7 tahun efektif meningkatkan keterampilan motorik kasar dan halus serta kemampuan membaca dan mengeja (Botha \& Africa, 2020), 8) program latihan perseptual motorik dapat mengembangkan kemampuan kelincahan, berlari, keseimbangan, koordinasi, dan kekuatan pada anak usia 8-11 tahun yang mengalami high function autistic disorder (Azar \& Akbar, 2018), 9) program perseptual motorik yang diberikan pada anak taman kanak-kanak usia 4-6 tahun dapat meningkatkan keterampilan motorik kasar dan halus (Sajedi \& Barati, 2014), 10) pengembangan perseptual motorik dapat dikembangkan secara optimal pada anak usia 3-6 tahun (Johnstone \& Ramon., 2011), 11) keterlibatan unsur-unsur perseptual motorik dalam tugas gerak, melalui sebuah bentuk permainan sangat perlu dilakukan oleh guru, agar menarik dan membuat siswa senang (Ningrum \& Sukoco, 2017), dan 12) Perceptual Motor Training (PMT) memberikan pengaruh terhadap perkembangan motorik kasar anak usia 5-6 tahun. Peningkatan motorik kasar anak dapat dilihat dari anak yang mampu untuk melakukan berbagai macam gerak lokomotor, gerak manipulatif, dan keseimbangan dengan benar dan terarah (Lukmawati et al., 2019). 
Hasil penelitian Yudanto (2018) telah mengembangkan model aktivitas jasmani berbasis perseptual motorik bagi anak taman kanak kanak. Penelitian ini menghasilkan model aktivitas berbasis perseptual motorik yang terdiri atas 8 (delapan) permainan berbasis tema, yaitu: permainan bertema diriku, permainan bertema keluargaku, permainan bertema lingkunganku, permainan bertema binatang, permainan bertema tanaman, permainan bertema kendaraan, permainan bertema alam semesta, dan permainan bertema tanah airku. Model aktivitas perseptual motorik yang telah dikembangkan tersebut, perlu dilakukan kajian lebih mendalam untuk mengetahui pengaruh terhadap gerak dasar, khususnya gerak dasar manipulatif untuk anak taman kanak-kanak. Tujuan penelitian ini untuk mengetahui pengaruh model aktivitas jasmani berbasis perseptual motorik terhadap gerak dasar manipulatif anak taman kanakkanak, yang meliputi: memukul bola diam, memantulkan bola di tempat, menangkap, menendang, lemparan atas, dan lemparan bawah.

\section{METODE}

Penelitian ini merupakan penelitian deskriptif kuantitatif dengan metode eksperimen. Desain penelitian menggunakan one group pre test and postest design. Subjek penelitian adalah anak taman kanak-kanak kelas B usia 5-6 tahun sebanyak 25 anak, yang terdiri atas 10 anak perempuan dan 15 anak laki-laki. Perlakuan yang diberikan berupa model aktivitas jasmani berbasis perseptual motorik melalui permainan berbasis tema, yang terdiri atas permainan bertema diriku, permainan bertema keluargaku, permainan bertema lingkunganku, permainan bertema binatang, permainan bertema tanaman, permainan bertema kendaraan, permainan bertema alam semesta, dan permainan bertema tanah airku, (Yudanto, 2018). Model aktivitas ini diberikan selama 30 hari. Instrumen penelitian menggunakan Test of Gross Motor Development-2 (TGMD-2) (Ulrich, 2000). Analisis data menggunakan uji t, hasil rata-rata tes awal dibandingkan dengan hasil rata-rata tes akhir. 


\section{HASIL}

Penelitian ini bertujuan mengetahui pengaruh model aktivitas jasmani berbasis perseptual motorik terhadap gerak dasar manipulatif anak taman kanak-kanak. Deskripsi data dapat dilihat pada tabel 1.

Tabel 1. Statistik Deskriptif Peningkatan Gerak Dasar Manipulatif

\begin{tabular}{|c|c|c|c|c|c|c|}
\hline \multirow{2}{*}{ Komponen } & \multirow[b]{2}{*}{$\mathbf{N}$} & \multicolumn{2}{|c|}{ Pre Test } & \multicolumn{2}{|c|}{ Post Test } & \multirow{2}{*}{$\begin{array}{c}\text { Persentase } \\
\text { (\%) } \\
\text { Peningkatan }\end{array}$} \\
\hline & & M & SD & M & SD & \\
\hline $\begin{array}{l}\text { Memukul bola } \\
\text { diam }\end{array}$ & 25 & 6.16 & 1.77 & 8.4 & 1.63 & 36.36 \\
\hline $\begin{array}{l}\text { Memantulkan } \\
\text { bola di tempat }\end{array}$ & 25 & 4.16 & 1.40 & 5.84 & 1.43 & 40.38 \\
\hline Menangkap & 25 & 3.76 & 1.74 & 5.44 & 1.19 & 44.68 \\
\hline Menendang & 25 & 6.32 & 1.18 & 7.84 & 0.47 & 24.05 \\
\hline Lemparan atas & 25 & 3.76 & 1.51 & 5.4 & 0.96 & 43.62 \\
\hline $\begin{array}{l}\text { Lemparan } \\
\text { bawah }\end{array}$ & 25 & 4.44 & 1.04 & 6.16 & 1.49 & 38.74 \\
\hline
\end{tabular}

Tabel 1 menunjukkan statistik deskriptif data kasar peningkatan gerak dasar manipulatif pada pre test dan post test. Komponen "memukul bola diam" mengalami peningkatan 36.36\%, komponen "memantulkan bola di tempat" mengalami peningkatan $40.38 \%$, komponen "menangkap" mengalami peningkatan $44.68 \%$, komponen "menendang" mengalami peningkatan $24.05 \%$, komponen "lemparan atas" mengalami peningkatan $43.62 \%$, dan komponen "lemparan bawah" mengalami peningkatan $38.74 \%$.

Tabel 2. Hasil Uji t Gerak Dasar Manipulatif Anak Taman Kanak-Kanak

\begin{tabular}{lcc}
\hline \multicolumn{1}{c}{ Komponen } & $\mathbf{Z}$ & Asymp. Sig. (2-tailed) \\
\hline Memukul bola diam & $-4.374^{\mathrm{b}}$ & 0.000 \\
Memantulkan bola di & $-4.304^{\mathrm{b}}$ & 0.000 \\
tempat & & \\
Menangkap & $-4.304^{\mathrm{b}}$ & 0.000 \\
Menendang & $-3.920^{\mathrm{b}}$ & 0.000 \\
Lemparan atas & $-4.165^{\mathrm{b}}$ & 0.000 \\
Lemparan bawah & $-4.288^{\mathrm{b}}$ & 0.000 \\
\hline
\end{tabular}

Tabel 2 menunjukkan hasil uji t seluruh komponen gerak dasar manipulatif nilai sig. $0.000<0.05$, maka ada pengaruh yang signifkan model aktivitas jasmani berbasis perseptual motorik terhadap gerak dasar manipulatif anak taman kanak-kanak. 
Yudanto

Pengaruh model aktivitas jasmani berbasis perseptual motorik terhadap gerak dasar manipulatif anak taman kanak-kanak

\section{PEMBAHASAN}

Hasil penelitian ini menunjukkan bahwa aktivitas jasmani berbasis perseptual motorik berpengaruh secara signifikan terhadap gerak dasar manipulatif pada anak taman kanak-kanak. Model aktivitas jasmani berbasis perseptual motorik yang digunakan sebagai perlakukan meliputi 8 (delapan) permainan berbasis tema, yang terdiri atas: permainan bertema diriku, permainan bertema keluargaku, permainan bertema lingkunganku, permainan bertema binatang, permainan bertema tanaman, permainan bertema kendaraan, permainan bertema alam semesta, dan permainan bertema tanah airku. Model aktivitas jasmani ini diberikan pada anak kelas B taman kanak-kanak usia 5-6 tahun selama 30 hari. Kemampuan gerak dasar manipulatif yang meliputi: memukul bola diam, memantulkan bola di tempat, menangkap, menendang, lemparan atas, dan lemparan bawah mengalami peningkatan, yang ditunjukkan dengan rata-rata post-test lebih besar dari pada rata-rata pre-test. Kemampuan memukul bola diam mengalami peningkatan dari 6.16 menjadi 8.4 atau meningkat $36.36 \%$, kemampuan memantulkan bola di tempat mengalami peningkatan dari 4.16 menjadi 5.84 atau meningkat $40.38 \%$, kemampuan menangkap mengalami peningkatan dari 3.76 menjadi 5.44 atau meningkat $44.68 \%$, kemampuan menendang mengalami peningkatan dari 6.32 menjadi 7.84 atau meningkat $24.05 \%$, kemampuan lemparan atas mengalami peningkatan dari 3.76 menjadi 5.4 atau meningkat $43.62 \%$, dan kemampuan lemparan bawah mengalami peningkatan dari 4.44 menjadi 6.16 atau meningkat $38.74 \%$.

Usia prasekolah sebagai masa yang penting dalam pekembangan dan penyempurnaan gerak dasar. Pada umumnya anak yang tumbuh normal mampu mempelajari dan mengembangkan gerakan-gerakan yang kompleks. Usia prasekolah dan tahun-tahun awal sekolah dasar sangat penting untuk pengembangan dan penguasaan kemampuan gerak dasar (Hardy et al., 2010). Upaya dalam mengembangkan kemampuan gerak dasar, agar diperoleh gerak yang berkembang dipengaruhi oleh kematangan syaraf dan otot. Hal ini sesuai dengan salah satu prinsip 
perkembangan motorik, yaitu perkembangan motorik tergantung pada kematangan otot dan syaraf (Sukamti, 2018). Kekayaan gerakan yang dimiliki oleh anak dan gerak yang menggambarkan suatu pola gerak juga berpengaruh pada berkembangnya gerak dasar.

Upaya mengembangkan kemampuan gerak dasar pada anak taman kanak-kanak dapat dilakukan melalui berbagai macam bentuk aktivitas jasmani berbasis perseptual motorik. Model aktivitas jasmani berbasis perseptual motorik, memberikan pengaruh pada kemampuan gerak dasar anak taman kanak-kanak. Hal ini sesuai dengan hasil penelitian: 1) perseptual motorik memiliki hubungan dengan kemampuan gerak dasar pada anak usia 5-7 tahun (Hyungmin \& Johan, 2012), 2) intervensi program perseptual motorik pada anak usia 6-7 tahun efektif meningkatkan keterampilan motorik kasar dan halus serta kemampuan membaca dan mengeja (Botha \& Africa, 2020), 3) program latihan perseptual motorik dapat mengembangkan kemampuan kelincahan, berlari, keseimbangan, koordinasi dan kekuatan pada anak usia 8-11 tahun yang mengalami high function autistic disorder (Azar \& Akbar, 2018), 4) program perseptual motorik yang diberikan pada anak Taman Kanak-Kanak usia 4-6 tahun dapat meningkatkan keterampilan motorik kasar dan halus (Sajedi \& Barati, 2014), 5) pengembangan perseptual motorik dapat dikembangkangkan secara optimal pada anak usia 3-6 tahun (Johnstone \& Ramon, 2011), 6) keterlibatan unsur-unsur perseptual motorik dalam tugas gerak, melalui sebuah bentuk permainan sangat perlu dilakukan oleh guru, agar menarik dan membuat siswa senang (Ningrum \& Sukoco, 2017) dan 7) Perceptual Motor Training (PMT) memberikan pengaruh terhadap perkembangan motorik kasar anak usia 5-6 tahun. Peningkatan motorik kasar anak dapat dilihat dari anak yang mampu untuk melakukan berbagai macam gerak lokomotor, gerak manipulatif, dan keseimbangan dengan benar dan terarah (Lukmawati et al., 2019).

Sesuai beberapa pendapat para ahli menyatakan bahwa anak usia dini adalah masa kritis bagi perkembangan kemampuan gerak dasar. 
Yudanto

Pengaruh model aktivitas jasmani berbasis perseptual motorik terhadap gerak dasar manipulatif anak taman kanak-kanak

Kemampuan gerakan dasar yang dimiliki tergantung pada beberapa faktor internal dan eksternal, seperti biologis, psikologis, sosial, motivasional, kognitif, dan lain-lain. Intervensi kemampuan gerak dasar pada prasekolah, berpengaruh pada penguasaan gerak dasar di sekolah dasar (Aryamanesh \& Sayyah, 2014). Kemampuan gerak dasar pada usia prasekolah sangat dibutuhkan dalam keterlibatan aktivitas fisik yang terstruktur maupun tidak terstruktur. Latihan kemampuan gerak dasar pada awal-awal di prasekolah memainkan peran penting dan menggambarkan perkembangan fisik, sosial, dan kognitif anak (Giannakidou et al., 2014). Kemampuan gerak dasar memiliki hubungan yang signifikan dengan aktivitas fisik sehari-hari (Fisher et al., 2005). Perkembangan gerak dasar anak, berperan penting untuk perkembangan kognitif, fisik, dan sosial, serta membangun fondasi untuk gaya hidup aktif (Hands \& Mclntyre, 2015). Hasil penelitian Ivonen dan kawan-kawan menyimpulkan bahwa aktivitas fisik sehari-hari pada anak prasekolah dipengaruhi oleh kemampuan gerak dasar (livonen et al., 2013). Kesempatan ideal bagi anak untuk belajar mengembangkan kontrol otot dan gerakan dilakukan pada usia dini. Anak usia dini masih menyukai gerakan dalam bentuk sederhana seperti melompat, meloncat, berlari, melempar, dan menendang (Nurtajudin, 2015). Anak usia 3-6 tahun dapat dianggap sebagai masa belajar keterampilan dan pengembangan keterampilan kasar dan halus (Sujarwo, 2015). Anak Taman KanakKanak, secara alamiah gemar mengeksplorasi gerak dan kegiatan sehariharinya didominasi oleh aktivitas gerak, perlu diberikan pengalaman dan keterampilan gerak dasar melalui aktivitas jasmani (Hartono et al., 2003). Aktivitas fisik gerak dasar pada masa kanak-kanak, yang meliputi gerak stabilitas, lokomotor, serta manipulatif yang diberikan melalui permainan akan menyenangkan (Rumini, 2014). Stimulasi untuk mengembangkan gerak dasar berperan dalan pembentukan bakat anak. Pada masa anak prasekolah perlu diberikan aktivitas multilateral yang mengembangkan semua aspek fisik (Sumantri, 2015). Berbagai macam keterampilan motorik kasar pada anak memberikan peran yang penting untuk aktivitas 
fisik dalam kehidupannya (Komputerisna, 2016). Pertumbuhan dan perkembangan anak dipengaruhi oleh kemampuan motorik yang dimilikinya. Kemampuan motorik yang terlambat akan berdampak pada pertumbuhan dan perkembangan yang terlambat juga (Fajar \& Permana, 2013).

Hasil penelitian Smith (2016) menunjukkan bahwa anak membutuhkan penguasaaan kemampuan gerak dasar sebelum mempelajari keterampilan dasar dalam suatu permainan. Penguasaan pola gerak dasar yang benar akan sangat menguntungkan pada saat mempelajari gerakan-gerakan yang komplek. Gerak dasar yang benar merupakan fondasi untuk gerak pada tahap penghalusan dan penampilan, sehingga akan mendapatkan kualitas gerak yang baik (Sutapa, 2002). Pengembangan unsur gerak dasar dalam model aktivitas jasmani berbasis perseptual motorik dalam penelitian ini meliputi gerak non lokomotor, lokomotor, dan manipulatif. Pengembangan unsur gerak dasar yang terdapat pada model aktivitas perseptual motorik, meliputi: 1) gerak dasar non lokomotor yang distimulasi dalam model aktivitas jasmani berbasis perseptual motorik diantaranya adalah menarik, memutar, dan menekuk; 2) gerak dasar lokomotor yang distimulasi pada model aktivitas jasmani berbasis perseptual motorik diantaranya adalah berlari, berjalan, melompat, meloncat, dan engklek; dan 3) gerak dasar manipulatif yang distimulasi pada model aktivitas jasmani berbasis perseptual motorik diantaranya adalah melempar, menangkap, memantulkan, memukul, dan menendang.

\section{KESIMPULAN DAN SARAN}

Penelitian ini menunjukkan bahwa pemberian model aktivitas jasmani berbasis perseptual motorik memberikan pengaruh yang signifikan terhadap gerak dasar manipulatif anak taman kanak-kanak. Kemampuan gerak dasar memukul bola diam, memantulkan bola di tempat, menangkap, menendang, lemparan atas, dan lemparan bawah mengalami peningkatan. Oleh karena itu, diharapkan guru penjas dapat menerapkan model aktivitas berbasis perseptual motorik, sebagai salah 
satu alternatif untuk meningkatkan gerak dasar manipulatif anak taman kanak-kanak.

\section{REFERENSI}

Affrida, E. N. (2017). Strategi Ibu dengan Peran Ganda dalam Membentuk Kemandirian Anak Usia Pra Sekolah. Jurnal Obsesi: Jurnal $\begin{array}{llll}\text { Pendidikan Anak Usia Dini, } 114 . & \end{array}$ https://doi.org/10.31004/obsesi.v1i2.24.

Aryamanesh, S., \& Sayyah, M. (2014). Effect of Some Selected Games on the Development of Locomotor Skills in 4-6 Year-Old Preschool Boys. International Journal of Sport Studies, 4(6), 648-652.

Azar, F. O., \& Akbar, P. S. (2018). The Effect of Perceptual Motor Training on Children's Development Motor Skills Aged B etween 8 to 11 with High Function Autistic Disorder ( HFA ). Indonesian Journal of Applied Science in Physical Education, 2(2), 1-11.

Bakhtiar, S. (2015). Merancang Pembelajaran Gerak Dasar Anak. Padang: UNP Press.

Botha, S., \& Africa, E. K. (2020). The Effect of a Perceptual-Motor Intervention on the Relationship between Motor Proficiency and Letter Knowledge. Early Childhood Education Journal, 0123456789. https://doi.org/10.1007/s10643-020-01034-8.

Dhingra, R., Manhas, S., \& Kohli, N. (2010). Relationship of Perceptual Abilities with Academic Performance of Children. Journal of Social Sciences, 23(2), 143-147. https://doi.org/10.1080/09718923.2010.11892823

Fajar, D., \& Permana, W. (2013). Perkembangan Keseimbangan pada Anak Usia 7 s/d 12 Tahun Ditinjau dari Jenis Kelamin. Jurnal Media IImu Keolahragaan Indonesia, $3(1)$. https://doi.org/10.15294/miki.v3i1.2657.

Fisher, A., Reilly, J. J., Kelly, L. A., Montgomery, C., Williamson, A., Paton, J. Y., \& Grant, S. (2005). Fundamental Movement Skills and Habitual Physical Activity in Young Children. Medicine and Science in Sports and Exercise, 37(4), 684-688. https://doi.org/10.1249/01.MSS.0000159138.48107.7D.

Giannakidou, D., Nastou, K., Karanatsiou, F., Pavlidou, S., \& Kambas, A. (2014). A Review of the Relationship between Physical Activity and Motor Proficiency in Children. European Psychomotricity Journal, 6(1), 52-59. https://doi.org/10.1016/j.langcom.2014.12.002

Hands, B., \& McIntyre, F. (2015). Assessment of Fundamental Movement Skills in Australian Children: The Validation Of A Fundamental Motor Skills Quotient (FMSQ). Malaysian Journal of Sport Science and Recreation, 11(1), 1-12. 
Hardy, L. L., King, L., Farrell, L., Macniven, R., \& Howlett, S. (2010). Fundamental Movement Skills Among Australian Preschool Children. Journal of Science and Medicine in Sport, 13(5), 503-508. https://doi.org/10.1016/j.jsams.2009.05.010

Hartono, M., Rahayu, T., \& Rustiadi, T. (2003). Model Belajar Gerak di Kanak-Kanak. Jurnal Nasional Pendidikan Jasmani Dan IImu Keolahragaan (National Journal of Physical Education and Sport Science), 2 (1).

Hidayatullah, M. F. (2019). Aktivitas Gerak pada masa Kanak-Kanak. Surakarta: Cakra Wijaya Press.

Hosseini, S. S., Panahi, M., Naghilo, Z., \& Ramandi, L. D. (2011). The Effect of Exercise Training on Perceptual Motor Skills and Physical Fitness Factors in Preschool Children. Middle-East Journal of Scientific Research, 9(6), 764-768.

Hyungmin, P., \& Johan, S. (2012). The Relation between Basic Movement Skills and Perceptual Motor Skills In 5 To 7 Years Old Children. European Journal of Neuroscience, 4(1), 57-65.

livonen, K. S., Sääkslahti, A. K., Mehtälä, A., Villberg, J. J., Tammelin, T. H., Kulmala, J. S., \& Poskiparta, M. (2013). Relationship between Fundamental Motor Skills and Physical Activity In 4-Year-Old Preschool Children. Perceptual and Motor Skills, 117(2), 627-646. https://doi.org/10.2466/10.06.PMS.117x22z7.

Johnstone, J. A., \& Ramon., M. (2011). Perceptual Motor Activities for Children: an Evidence Based Guide to Building Physical and Cognitive Skills. USA: Human Kinetic.

Komputerisna, A. A. (2016). Gross Motor Skills of The Childrenâs Group a Judging from Demonstration Method of Motion and Song in Kindergarten Pertiwi Nusa Indah. BELIA: Early Childhood Education Papers, 5(1), 1-5.

Lukmawati, L., Sriyanto, M. I., \& Syamsuddin, M. M. (2019). Pengaruh Perceptual Motor Training (PMT) terhadap Perkembangan Motorik Kasar pada Anak Usia 5-6 Tahun. Kumara Cendekia, 7(2), 175. https://doi.org/10.20961/kc.v7i2.36386.

Macdonald, K., Milne, N., Orr, R., \& Pope, R. (2020). Associations between Motor Proficiency and Academic Performance in Mathematics and Reading in Year 1 School Children: A CrossSectional Study. BMC Pediatrics, 20(1), 1-11. https://doi.org/10.1186/s12887-020-1967-8.

Morales, J., Gonzales, L. M., Guerra, M., Virgili, C., \& Unnithan, V. (2011). Physical Activity, Perceptual Motor Performance, and Academic Learning in 9 to 16 Years Old School Children. International Journal of Sport Psychology, 42: 401-41.

Ningrum, N. F. M., \& Sukoco, P. (2017). Pengembangan Model 
Permainan untuk Meningkatkan Perseptual Motorik dan Perilaku Sosial Siswa Sekolah Dasar Kelas Bawah. Jurnal Keolahragaan, 5(2), 171. https://doi.org/10.21831/jk.v5i2.7905

Nourbakhsh, P. (2006). Perceptual Motor Abilities and their Relationships with Academic Performance of Fifth Grade Pupils in Comparison with Oseretsky Scale. Kinesiology, 38(1), 40-48.

Nurtajudin. (2015). Pengaruh Latihan Koordinasi Mata-Kaki-Tangan dan Tingkat Keseimbangan terhadap Motorik Kasar Anak Usia Dini. Journal of Physical Education and Sports, 4(2), 154-158.

Rachman, H. A., \& Anggita, G. M. (2018). The Development Pattern of Early Age Children's Motor Skills. Journal of Physical Education, Sport, Health and Recreations, 7 (2), 104-112.

Rumini. (2014). Pembelajaran Permainan Kids' Atlhletics sebagai Wujud Pengembangan Gerak Dasar Atletik pada Anak-Anak. Journal of Physical Education, Health and Sport, 1 (2).

Sajedi, F., \& Barati, H. (2014). The Effect of Perceptual Motor Training on Motor Skills of Preschool Children. Iranian Rehabilitation Journal, 12(19), 14-17.

Smith, W. (2016). Fundamental Movement Skills and Fundamental Games Skills are Complementary Pairs and Should be Taught in Complementary Ways At All Stages Of Skill Development. Sport, Education and Society, 21(3), 431-442. https://doi.org/10.1080/13573322.2014.927757.

Sugiyanto. (2005). Perkembangan dan Belajar Motorik. Jakarta: Universitas Terbuka.

Sujarwo. (2015). Kemampuan Motorik Kasar dan Halus Anak Usia 4-6 Tahun. Jurnal Pendidikan Jasmani Indonesia, 11(2), 96-100. https://doi.org/10.21831.

Sukamti, E. R. (2018). Perkembangan Motorik. Yogyakarta: UNY Press.

Sumantri, M. S. (2015). Learning Model of Fundamental Long Jump Movement Based On Game Approach. Indonesian Journal of Early Childhood Education Studies, 4(1), 35-41. https://doi.org/10.15294/ijeces.v4i1.9451.

Sutapa, P. (2002). Pengamatan Pola Perkembangan Motorik Anak Sebagai Langkah Awal Pemninaan Calon Olahragawan. Majalah Olahraga, 8 (1).

Ulrich, D. A. (2000). Test of Gross Motor Development: Second Edition. Texas: Pro.ed An International Publisher.

Yudanto. (2018). Model Aktivitas Jasmani Berbasis Perseptual Motorik untuk Mengembangkan Multiple Intelligences bagi Peserta Didik Taman Kanak-Kanak. Disertasi. Universitas Negeri Semarang. 